OPEN ACCESS

Edited by:

Fan Tong,

Lawrence Berkeley National Laboratory, United States

Reviewed by:

Meiyu Guo,

Hong Kong Baptist University,

Hong Kong

Ilhan Ozturk,

Çağ University, Turkey

*Correspondence:

Gang Lin

lgcumtb@outlook.com

Ruiwen Yan

yanruiwen819@hotmail.com

Specialty section: This article was submitted to

Sustainable Energy

Systems and Policies,

a section of the journal

Frontiers in Energy Research

Received: 03 May 2020 Accepted: 27 August 2020 Published: 23 September 2020

Citation:

Li X, Dong D, Lin G, Yan R and Li S (2020) Water Use for Energy

Production and Conversion in Hebei Province, China.

Front. Energy Res. 8:558536. doi: 10.3389/fenrg.2020.558536

\section{Water Use for Energy Production and Conversion in Hebei Province, China}

\author{
Xiang $\mathrm{Li}^{1}$, Donglin Dong ${ }^{1}$, Gang $\mathrm{Lin}^{2,3 *}$, Ruiwen $\mathrm{Yan}^{1 *}$ and Shuqian $\mathrm{Li}^{1}$ \\ ${ }^{1}$ College of Geoscience and Surveying Engineering, China University of Mining and Technology, Beijing, China, ${ }^{2}$ Institute of \\ Geographical Sciences and Natural Resources Research, Chinese Academy of Sciences, Beijing, China, ${ }^{3}$ State Key Laboratory \\ of Resources and Environmental Information System, Beijing, China
}

In recent years, with the socio-economic development, energy production and water consumption have been given more and more scientific, political and public concern. Taking Hebei Province, China as, an example, this paper performs an in-depth analysis of the energy production and water consumption. In this study, the water withdrawals and water consumption associated with energy production in Hebei Province from 2015 to 2050 were estimated by using the bottom-up Long-range Energy Alternative Planning model, which established three scenarios based on three different development models. The results show that the energy production and their associated water requirements would continue to grow at a high speed in the Reference Scenario. The energy production and their associated water withdrawals and water consumption were found to have decreased sharply in the coordinated development scenario and the strong emission reduction scenario compared to the reference scenario. It shows that industrial restructuring, energy structure optimization and the renewable energy replacement have played an important role in energy-efficient and water-efficient in coordinated development scenario and strong emission reduction scenario. Further coordinated management policy on water and energy should be fully considered to promote the sustainable management of water and energy in Hebei Province.

Keywords: energy production, water requirements, energy-water nexus, Long-range Energy Alternative Planning model, Hebei

\section{INTRODUCTION}

Water and energy resources are significant material foundations for the development of human society and a powerful driving force for the modernization process (Spang et al., 2014; Qin et al., 2015). However, in the context of global climate change and an increasing population, we are facing many problems regarding the demand for water resources and energy. The UN Sustainable Development Goals proposed in 2015 pointed out that, as the global economy grows year by year, despite the improvement in energy efficiency, energy use will have grown by $35 \%$ by 2020 , and the world's energy consumption will increase by nearly $50 \%$ over the next 30 years (Bureau for Workers' Activities, 2014). At the same time, $<3 \%$ of the world's water will be fresh, and it is estimated that two-thirds of the world's population will face water shortages by 2025 (Lu et al., 2015). Therefore, one of the objectives of the United Nations (UN) World Water Day, which has the theme of "Water and Energy," is to call on countries to implement more "coordinated, coherent, and consistent" sustainable development policies for energy and water resources. 


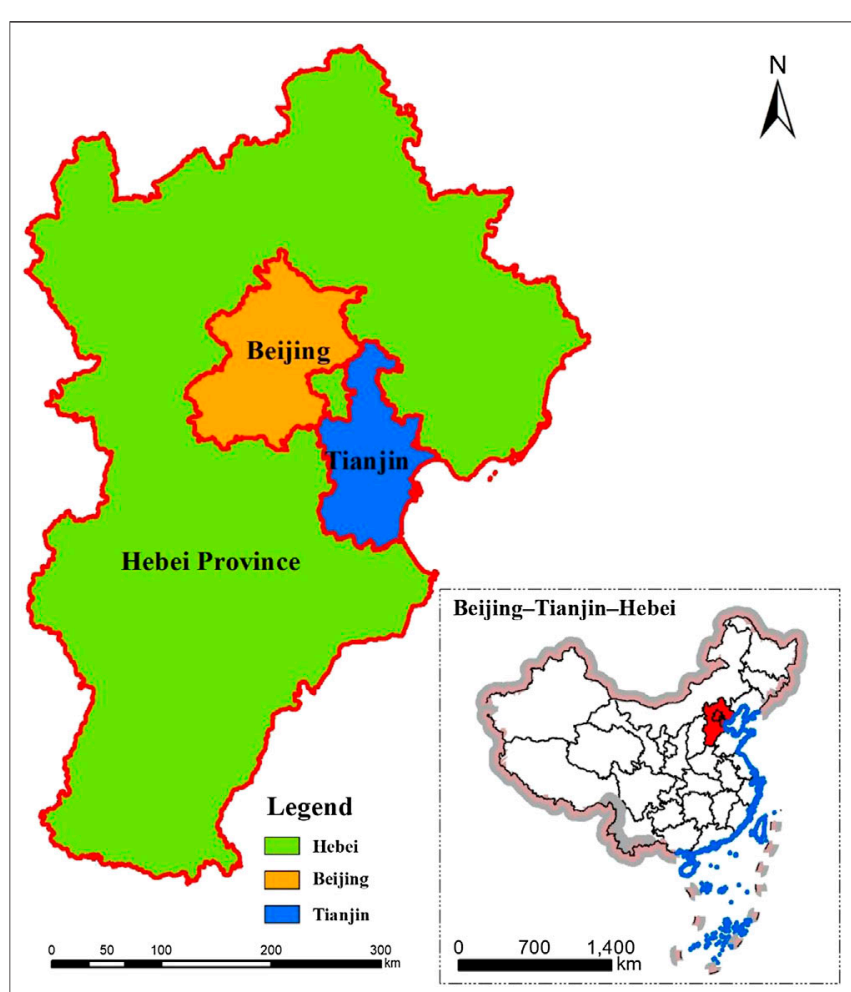

FIGURE 1 | The location of the study region in China.

Hebei Province $\left(\mathrm{E} 113^{\circ} 27^{\prime}-119^{\circ} 50^{\prime}, \mathrm{N} 36^{\circ} 05^{\prime}-42^{\circ} 40^{\prime}\right)$ is located on the shores of the Bohai Sea. Its inner ring contains the cities of Beijing and Tianjin, and it is one of China's primary industrial bases (Figure 1). It holds a critical strategic position in the integrated development of Beijing-Tianjin-Hebei (Jing-Jin-Ji). Hebei is a major energy and industrial center and faces population pressure, resource shortages, and environmental pollution. Hebei Province is rich in energy resources but seriously lacks water resources, and there is typically a serious mismatch between the energy and water resources distribution patterns. The energy industry is responsible for a large part of the water use of the industries in Hebei province. The exploitation and processing of traditional energy consumes a lot of fresh water every year, but Hebei Province is seriously deficient in water resources. The water resources per capita are $386 \mathrm{~m}^{3}$, the water resources per acre are $243 \mathrm{~m}^{3}$, and the water resources per capita and acre are equivalent to one-eighth of the national average value (Ministry of Water Resources of China, 2015).

The continuous increase in demand for energy poses enormous challenges for water use and safety in Hebei Province. In the functional orientation of the "Beijing-Tianjin-Hebei (Jing-Jin-Ji) Collaborative Planning Outline," Hebei Province is considered to be an area that supports the Beijing-Tianjin-Hebei ecological environment and plays an important role in the utilization of ecological resources and environmental protection. It is a typical regional economic area and a significant hub for the integration of JingJin-Ji. However, the primary industry and the secondary industry require a large amount of imported water due to the fact that the local water resources cannot meet their total water demand. Considering the implement of the recent development plan ("The development of Xiongan New Area" and the "Two-child Policy"), hosting the Winter Olympic Games, and the technological innovation in the energy sector, without a doubt, it will exert great influence on the tense relationship between water and energy in Hebei Province. At this stage, studies focused on Hebei is commonly found on water-energy nexus and the decomposition analysis of water utilization in Jing-Jin-Ji region (Wang et al., 2015; Sun et al., 2018; Li X. et al., 2019). Specifically, for Hebei Province, Lv et al. (2018) identified optimal strategies for the energy-water nexus system under multiple uncertainties and various water-saving scenarios ( $\mathrm{Lv}$ et al., 2018). However, few studies are employed to perform an in-depth analysis of the energy production and their associated water consumption under a multi-scenario analysis considering the low-carbon and sustainable policy in Hebei Province. Thus, this study established a multi-scenario analysis of water requirements for energy production in Hebei province using the Long-range Energy Alternative Planning (LEAP) model via comprehensively considering the corresponding policy of the development of a low-carbon economy. Furthermore, the paper explores the trend of change in water demand for energy production under the influence of the corresponding greenhouse gas emission policies in Hebei Province as well as the water use problems in the energy industry. The results of this study may provide a scientific basis for decision-making to improve the management of energy and water use and implement sustainable energy and water resource development policies, and be conducive to the sustainable development of the Beijing-Tianjin-Hebei region.

The paper is organized as follows: Introduction section introduces motivation and objective and contribution of this study; Literature Review briefly reviews the previous literatures; Methodology and Data describes the methodology and data; Empirical Results and Discussion present the empirical results and discussion of this work; conclusions and policy implications are presented in the final section.

\section{LITERATURE REVIEW}

In recent years, energy production and water restrictions have attracted more and more scientific, political and public concern. Water withdrawals and water consumption for energy production always serve as key indicators for assessing the water use in energy production. Water withdrawals refer to the diverted or withdrawn water from a surface or groundwater source while water consumption is the consumed part (evaporation, absorbed by a product, or other losses) of withdrawn water from natural water bodies (Strzepek et al., 2012).

To date, researches on water use for energy extraction, processing, and conversion widely reported, including traditional fossil fuel production (coal, oil, and natural gas), heat and electricity generation, the production of energy from biomass, and the impact of water use in the energy production 
process on the ecological environment (Veil et al., 2004; Mielke et al., 2010; Zhou et al., 2016). In addition, the policy implications for managing the two resources have been assessed at the national level, where energy and water management are generally independently regulated (Pate et al., 2007). Many scholars have commented on the content of sustainable development policies for both energy and water resources, including the sustainable development of wind, solar, and biomass energy sources, an energy conservation policy, a climate policy, the sustainable development of water resources, the three Red Lines water policy, and technological innovation (Kiparsky et al., 2013; Qin et al., 2015; Zhou et al., 2016). The results of most of the abovementioned energy production studies are based on the research results of other studies and not on regional policies. For example, according to the energy strategy scenario of China's International Energy Agency (IEA), Cai et al. (2014) evaluated the water withdrawals for energy production from 2011 to 2030 (Cai et al., 2014), and Qin et al. (2015) assessed the water use in the energy industry and its impact on the " 3 Red Lines water policy" (Qin et al., 2015). Based on a multiregional inputoutput analysis, Jin et al. (2019) investigated the water-energy nexus networks in China, which provided valuable reference for synergetic development of water and energy resources (Jin et al., 2019). However, few of the studies are employed to performs an in-depth analysis of the energy production and their associated with water consumption with a multi-scenario analysis considering the low-carbon and sustainable policy in Hebei Province.

There are three main approaches to calculate the water requirements for energy production. One is to use a technology-based bottom-up approach to calculate water use (water withdrawals or water consumption) in the energy sector, which is calculated by multiplying the energy production by the water use coefficients of a range of energy technologies, including fossil-fuel-based energy production and power generation (Veil et al., 2004; Kenney and Wilkinson, 2011; Nicot and Scanlon, 2012; Zhou et al., 2016; Zhou et al., 2019). Another approach is to use a hybrid strategy consisting of a lifecycle approach and an input-output approach (Cooper and Sehlke, 2012; Fang and Chen, 2016). The third approach is to use the scenario analysis method, which simulates water requirements in the medium- and long-term for energy production by setting different conditions (Cooper and Sehlke, 2012; Shang et al., 2016). The bottom-up approach is a simple and effective way to calculate local and overall water usage. The hybrid approach is more rigorous, but its data requirements are strict. The scenario analysis method can be used to set changes in different conditions and conduct medium- and long-term simulations of energy production and water requirements.

\section{METHODOLOGY AND DATA}

\section{Methodology \\ The Framework of the Model}

In view of the complex relations between water use, energy production, and socio-economic factors, the LEAP-Hebei model was adopted in this research to perform a systematic analysis of current and future energy production and the associated water use. Figure $\mathbf{2}$ presents the model's framework, which was applied to assess the water use for energy production in Hebei Province.

\section{The Long-range Energy Alternative Planning Model}

The bottom-up approach can be used to calculate a local or an overall water use value. At this stage, most studies on water use for energy production use bottom-up accounting methods to calculate the water use value in the energy sector. These studies multiply the energy production by the water use coefficient of a range of energy technologies. The LEAP model was developed by the Stockholm Environment Institute in Boston. It is a bottom-up model and can be applied to perform a comprehensive analysis of the energy-economyenvironment nexus based on different planning scenarios (Clark and Heaps, 2012). Different scenarios can be set up in the model, and different policy measures and technical means can be adopted to carry out medium- and long-term simulations of energy supply, energy consumption, and environmental conditions by linking the environmental emissions and the driving factors in the study area (Cai et al., 2008). It is widely used on global, national, and local scales to predict energy supply and demand and the impact of energy policy changes on the environment. Based on the LEAP model, Chen et al. (2020) established four scenarios to estimate China's energy demand and carbon emissions from 2020 to 2050. Katta et al. (2019) simulated energy demand and supply of Canada's oil sands from 2007 to 2050. Agrawal et al. (2018) developed an integrated framework to analyze the impact of climate change on water consumption and greenhouse gas emissions. Zhao et al. (2011) analyzed the path of China's development of a low-carbon economy by 2050 . Hong et al. (2016) used the LEAP model to discuss the effectiveness of policies imposed on the Korean transportation sector, and the chain effect on Korea's energy and environment by 2050. Rahman et al. (2016) combined SMAA (Stochastic Multicriteria Acceptability Analysis) with the LEAP model to promote multi-sector-related interests and plan energy policies to achieve a sustainable low-carbon path. Emodi et al. (2017) used the LEAP-Ningbo model to simulate the greenhouse gas emissions of the six energy sectors in Ningbo, which is a pilot lowcarbon city. In summary, the LEAP model is a bottom-up, longterm energy planning model. Most current research focuses on energy forecasting and carbon emissions simulation, but there is relatively little research on water use for energy production using the LEAP model. In this study, we combined the LEAP model with energy production forecasting to analyze water use for the energy sector.

\section{Water Withdrawals and Consumption}

Most of the energy scenarios that are currently used to study energy production and water use are based on the research results of other studies and do not fully integrate the policies in the study area. In this paper, we concentrate on current and future water use for energy production by first applying policies on economic growth, energy utilization (clean energy), industrial structure, 
Technology-Economic and Environment Data Collection

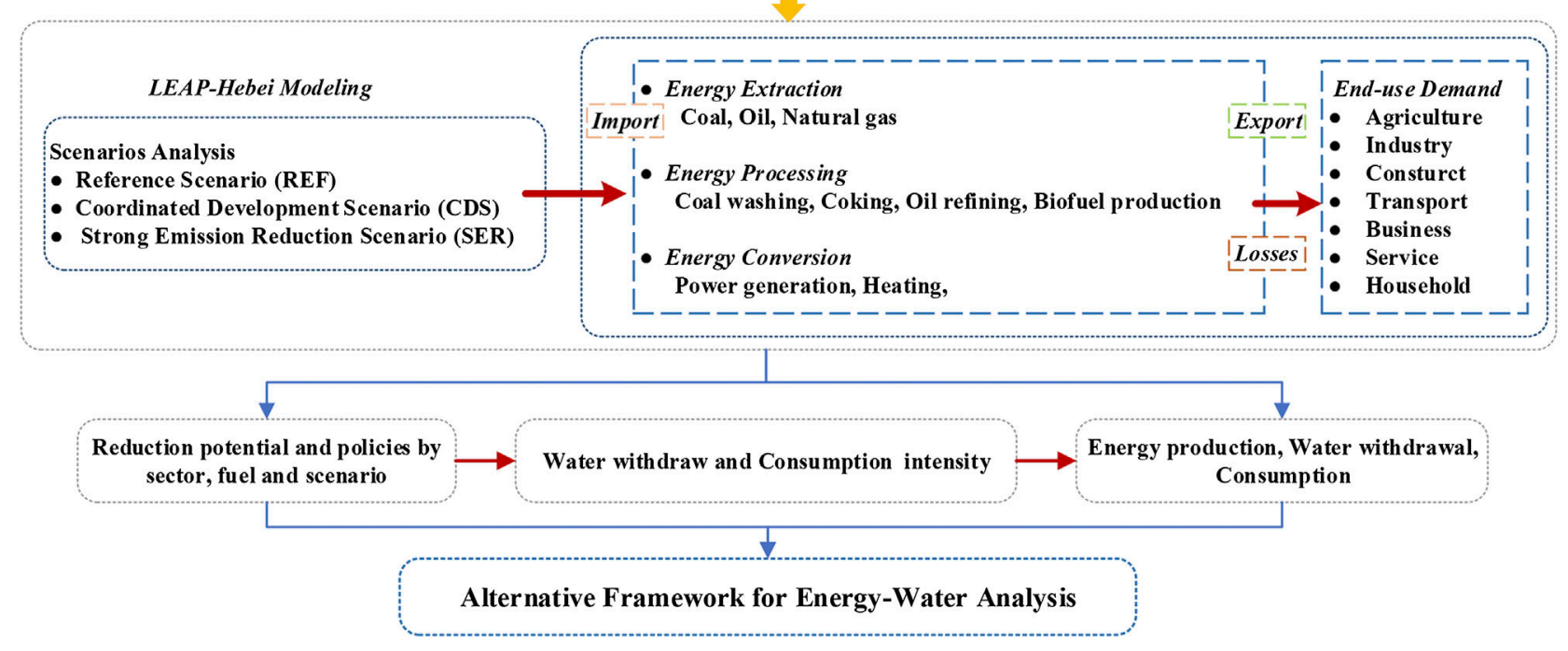

FIGURE 2 | The model's framework.

and innovative technology in a bottom-up approach based on the establishment of the LEAP-Hebei model. The water use for energy production was calculated by multiplying the energy production of each sector by the intensity of water withdrawals and the intensity of water consumption to calculate the water withdrawals and water consumption, respectively, of various types of energy production.

$$
\begin{gathered}
W=\sum_{i=1}^{n} E_{i} \alpha_{i} \\
C=\sum_{i=1}^{n} E_{i} \beta_{i}
\end{gathered}
$$

where $E_{i}$ represents the $i$-type energy production, $W$ represents the water withdrawals for the energy production, $C$ represents the water consumption for the energy production, $n$ represents the total number of energy production types, and $\alpha_{i}$ and $\beta_{i}$ indicate the $i$-type intensity of water withdrawals and consumption for the energy production, respectively.

\section{Scenario Settings}

The proposed scenario is based on the Hebei 13th Five-Year Plan, the Hebei Town Planning System, China's recent "Climate Planning," and the 2050 China Energy and Carbon Emissions Report. Three scenarios were established based on the activity level of each energy sector, the energy intensity, and the energy structure by the bottom-up approach. The key data and assumptions, including Gross Domestic Product (GDP), population, and urbanization, were set to be the same in order to compare the results from the three scenarios. Regarding the settings of the scenarios in Hebei province, reference was made to the research of Li Z. et al. (2019). As a basic scenario, the reference
(REF) scenario is consistent with the REF scenario of Li Z. et al. (2019), representing the existing development status of Hebei Province. The coordinated development scenario (CDS) comprises the industry structure optimization scenario and the terminal consumption structure optimization scenario, which are based on the REF scenario, and optimize the industrial structure and energy structure, inhibit the development of the secondary industry, vigorously develop the tertiary industry, improve energy efficiency, implement natural gas instead of coal, develop renewable energy, and increase the proportion of renewable energy. The strong emission reduction (SER) scenario is referenced to the low-carbon development scenario, and the other key parameters refer to the settings described in this article. The SER scenario is based on the CDS scenario, and further improves energy efficiency, implements natural gas instead of coal, develops renewable energy, focuses on the development of wind and solar energy, which, in this scenario, become the energy sources with the dominant proportion of power generation, and introduces advanced carbon capture and storage (CCS) technology to reduce carbon emissions from thermal power generation. The major parameters that were used in the sub-sectors of the REF, CDS, and SER scenarios in the LEAP-Hebei model are given in Supplementary Tables S2-S6.

There are many technologies that can reduce the amount of water use for energy production, most notably cooling technology. In this paper, the parameters for change in consideration of the development of water-saving technology were set for the future. The intensity of water withdrawals and water consumption remained unchanged at the base year in REF. The other two scenarios take into account the development of water-saving technology, and the intensity of water withdrawals and the intensity of water consumption are estimated from the 
TABLE 1 | The cooling technology in the future setting [the coordinated development scenario and the strong emission reduction scenario] in the model.

\begin{tabular}{lccccc}
\hline Cool technology & $\mathbf{2 0 1 5}$ & $\mathbf{2 0 2 0}$ & $\mathbf{2 0 3 0}$ & $\mathbf{2 0 4 0}$ & $\mathbf{2 0 5 0}$ \\
\hline Once-through cooling & 0.05 & 0.04 & 0.03 & 0.02 & 0.01 \\
Cyclic cooling & 0.66 & 0.61 & 0.55 & 0.50 & 0.42 \\
Air-cooling & 0.12 & 0.18 & 0.25 & 0.31 & 0.40 \\
\hline
\end{tabular}

scenario. The proportion of the three cooling technologies in the three scenarios is based on (Zhang et al., 2014; Zhou et al., 2016). The future cooling technology development ratio parameters (excluding seawater cooling) were set as shown in Table $\mathbf{1 .}$

\section{Data Acquisition Data Collection}

The data for the modeling process that were collected for this research included: historical data on Hebei Province, baseline data from 2015, trend data, and reference parameters. The historical data were used for key assumptions and scenarios, such as industry added value, urbanization, population, and GDP, and were primarily statistics from the Hebei economic statistics yearbook (2000-2016) (Li et al., 2018), the sixth Hebei population census, and town planning in Hebei province (Wang and Yang, 2015; Department of Housing and Urban-Rural of Hebei, 2017). The baseline data from 2015 were statistics taken from the Hebei Economic Yearbook of 2016 and the China Energy Statistics Yearbook of 2016 (China Electric Power Yearbook Editorial Committee, 2016) regarding energy supply, imports and exports, transformations, input, and demand in seven sectors. The trend data (changes in industrial structure and changes in energy efficiency) and some binding indicators were obtained from government and special department planning documents. The government department survey data were taken from Hebei's 13th five-year energy development plan, reports from academic institutions in various departments of Hebei, the program for the coordinated development of Beijing-Tianjin-Hebei, and China's Energy and Carbon Report 2050 (China energy and Carbon Emission Research Group, 2009; Department of Housing and Urban-Rural of Hebei, 2017; Zhou et al., 2017). The reference parameter data were derived from the "General Calculation Rules for Integrated Energy Consumption" (GB/T-2589-2008), the energy conversion standard coal coefficient, and the average low heat generation of energy, which are all contained in Appendix 4 of the China Energy Statistics Yearbook of 2016 (China Electric Power Yearbook Editorial Committee, 2016).

The estimations of water withdrawals and consumption for energy production were found to vary widely across the following sources of information: the National Pollution Source Survey of China (Zhang et al., 2013), The Chinese Environmental Statistics Database of 2011 (Lv et al., 2018), and other research data (Qin et al., 2015). In this study, the water withdrawals coefficient was based on (Zhang et al., 2013; Lv et al., 2018), and the water consumption coefficient was based on (Zhang and Anadon, 2013; Zhou et al., 2016). The water withdrawals and consumption factors that were used in this paper are provided in Supplementary Table S1.

\section{Accounting Scope}

In this study, water withdrawals and water consumption were assessed in the energy sector. Energy production included primary energy (coal, oil, and natural gas) extraction. The primary energy processes included processes for washing coal, coking, refining oil, and biofuel production. Primary energy conversion included coal power generation, natural gas power generation, biomass power generation, nuclear power, hydropower, wind power, and solar power generation and heating.

Considering that wind energy and nuclear energy are not widely used in Hebei, the water use for wind energy and nuclear energy were not taken into consideration (Chen et al., 2016). In the future, the use of solar energy and photovoltaic power generation will continue to grow in Hebei, and about $0.019 \mathrm{~m}^{3} / \mathrm{MW} \mathrm{h}$ of water will be used when cleaning the surfaces of battery components (Macknick et al., 2012). Hydropower, according to some studies, is considered to be a water-intensive energy carrier (Liu et al., 2015; Zhou et al., 2016). Biomass power generation only accounts for a small part of the total power generation in Hebei Province, and uses crop straw and garbage as fuel. In this study, we did not consider the water that was used in the production of biological raw materials; we only considered water consumption during power generation (Cai et al., 2014). In this paper, we analyzed the use of fresh water in energy production in Hebei Province; accordingly, the utilization of seawater fell outside the accounting scope. A power plant's cooling technology has a great impact on water withdrawals and water consumption. Three types of cooling systems were considered in our research: once-through, cyclic, and air-cooling. Only the "operable" water withdrawals and the water consumption that was directly related to energy production were considered in this research.

\section{EMPIRICAL RESULTS AND DISCUSSION}

\section{Results and Analysis \\ The Predicted Results for Energy Demand and Production}

Figure 3 shows the long-term energy demand trend in Hebei Province. There are no inflection points in any of the three scenarios. There is an increasing trend during the projection period in the REF and CDS scenarios. The SER scenario also shows an upward trend; however, the growth rate is slow. The total energy demand in the SER scenario increased from 321,618 Mtce in 2015-2,253.13 Mtce in 2050, with an average annual growth rate of $5.72 \%$.

Figure 4 shows the energy production in Hebei Province. There is an increasing trend during the projection period in the REF and CDS scenarios; however, in the SER scenario, the energy production peaked around 2030 due to strict control policies and then slowly declined. The energy production in the SER scenario decreased significantly compared to the REF and CDS scenarios. The energy production in the REF, CDS, and SER scenarios reaches $826.04,547.01$, and 340.30 Mtce, respectively, in 2050. In the REF scenario, traditional fossil fuels dominate the period 


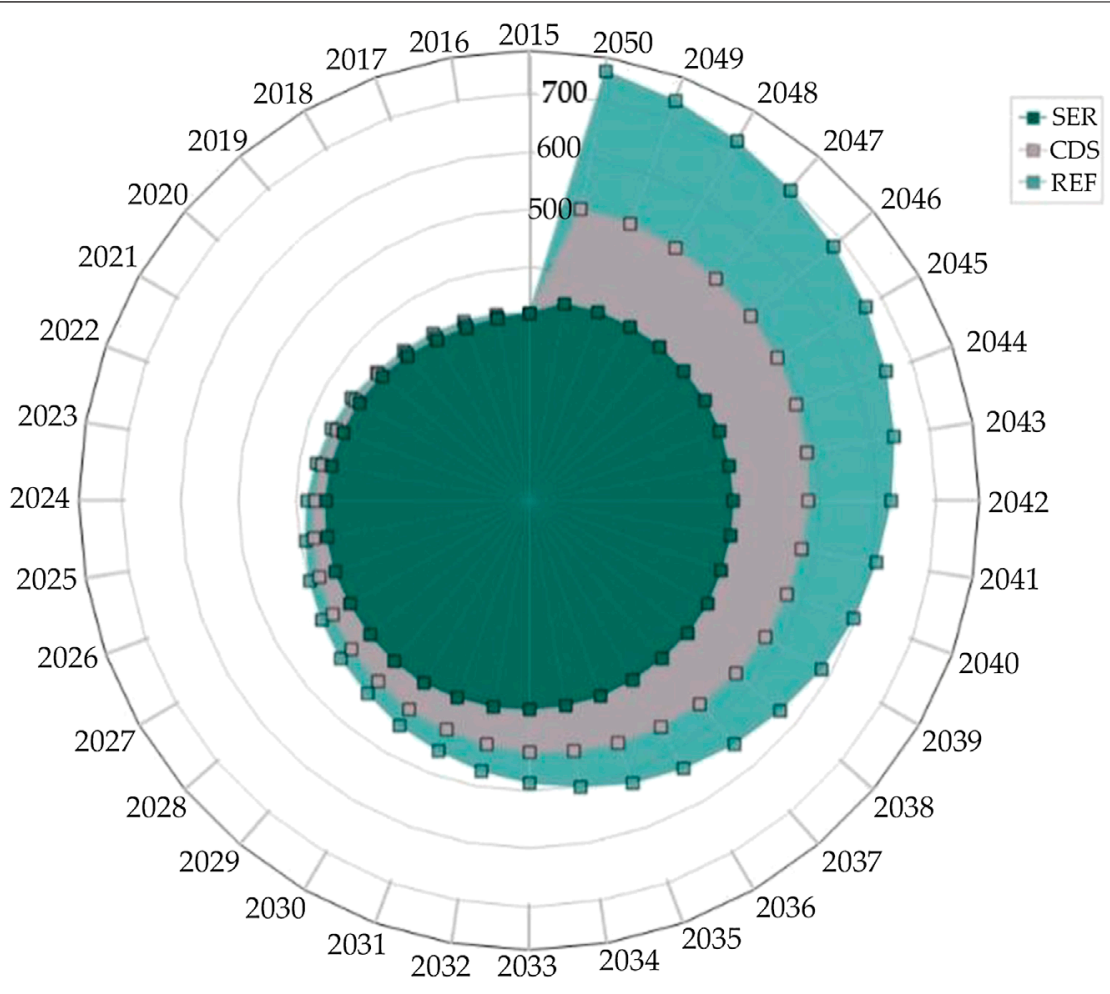

FIGURE 3 | The energy demand in the three scenarios during the period 2015-2050.

2015-2050; consequently, in this scenario, the coal industry accounts for the highest proportion of energy production among the various industries. In the CDS scenario, the total coal output and energy production in 2030 and 2050 decreased by approximately 19.78 and $39.47 \%$, respectively, compared with the REF scenario. In the SER scenario, the production of natural gas shows an upward and then a downward trend. Renewable energies, such as wind and solar energy, become the main

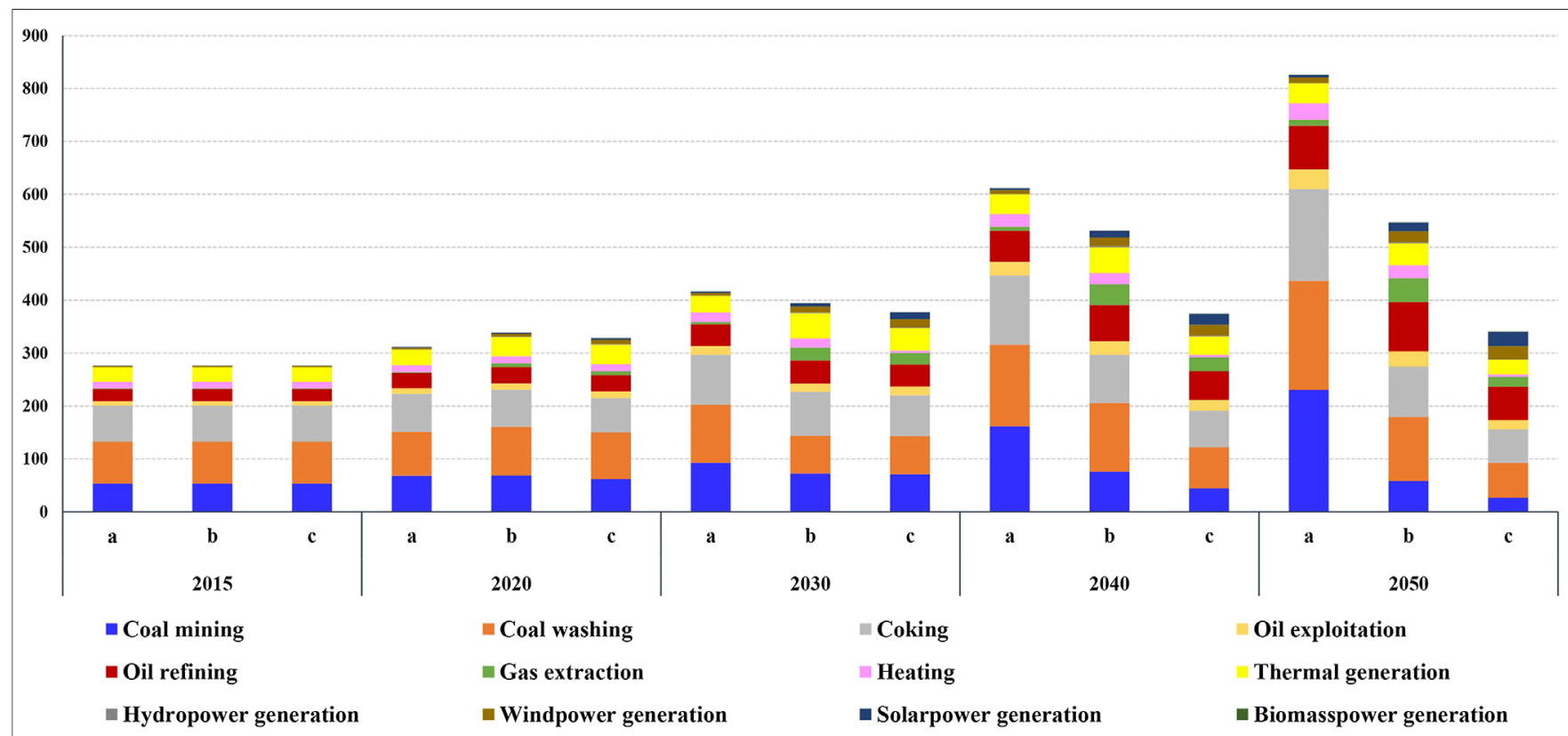

FIGURE 4 | The energy production of each sector in the three scenarios: (a) reference, (b) coordinated development scenario, (c) strong emission reduction (the detailed data was shown in Supplementary Table S7). 


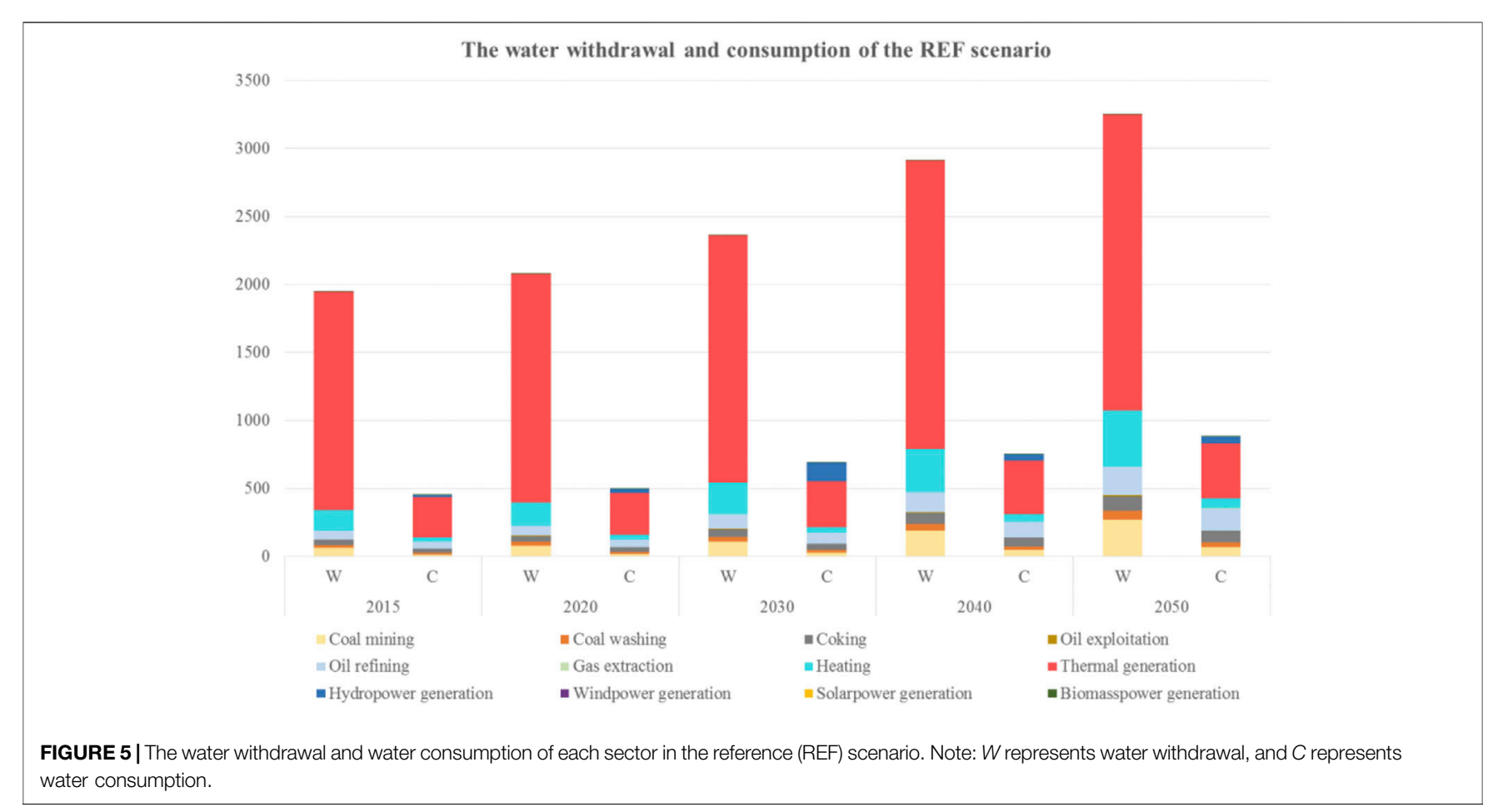

sources of energy. The production of coal, oil, and natural gas decreased by approximately 43.09, 34.34, and 59.60\%, respectively, the production of wind energy increased by approximately $28.45 \%$, and the production of solar energy increased by approximately $62.96 \%$ compared with the CDS scenario in 2050. Renewable energy gradually becomes an important energy, and the gradual expansion of renewable energy use also effectively reduces $\mathrm{CO}_{2}$ emissions.

\section{Water Withdrawals and Water Consumption for Energy Production}

The amount of water required for energy production is affected by changes in energy production and different policies will have different effects on energy production. Three different scenarios, as shown in Figures 5-7, were analyzed in this paper. A comparison of the three scenarios shows that, in the REF scenario, the energy structure was not adjusted, energy production is on the rise, and water withdrawals and water consumption for energy production are also on the rise. In the CDS scenario and the SER scenario, the water withdrawals and water consumption for energy production first increase and then decrease, and reach their peak in 2020 and 2030, respectively.

As shown in Figure 5, the REF scenario represents a continuation of the existing status. The water withdrawals requirements for energy production will increase to 2.08, 2.36, 2.91 , and 3.25 billion $\mathrm{m}^{3}$, and the water consumption for energy production will increase to $0.45,0.50,0.59,0.75$, and 0.88 billion $\mathrm{m}^{3}$, in 2020, 2030, 2040, and 2050, respectively, Comparing 2015 with 2050, the water withdrawals and water consumption will increase by 66.80 and $95.68 \%$, respectively, and the average annual growth rate of water withdrawals and water consumption will increase by 5.60 and $5.72 \%$, respectively. This will pose a serious challenge to the protection of water resources in Hebei province. In terms of water withdrawals by 2050, about $72.43 \%$ of the water will be used for thermal power generation, and $7.76 \%$ of the water will be used by the heating industry. Coal mining, coal washing, coking, oil extraction, oil refining, and natural gas extraction account for $9.80 \%$ of the total water consumption. In terms of water consumption by 2050, coal mining, coal washing, coking, oil extraction, oil refining, and natural gas mining account for approximately $36.19 \%$, the heating industry accounts for approximately 5.55\%, and power industry's water consumption accounts for approximately $58.25 \%$, of which thermal power accounts for approximately $56.06 \%$ of the total water consumption.

As shown in Figure 6, the water withdrawals and water consumption for energy production decreased sharply compared with the REF scenario. The water withdrawals and water consumption first increased and then decreased, and both the water withdrawals and the water consumption peaked around 2030. The water withdrawals decreased by 33.58 and $73.09 \%$ and the water consumption decreased by 26.95 and $57.58 \%$ compared with the REF scenario in 2030 and 2050, respectively. In the CDS scenario, the project to replace coal with natural gas is adopted, which causes the water used in coal mining and coal washing to reach a peak around 2040, with an inflection point. The amount of water used for thermal power generation peaks around 2030, then slowly declines, and the other sectors continue with an upward trend. In terms of water withdrawals by 2050, the proportion of thermal power generation will remain the largest, accounting for approximately $50.30 \%$ of the total value, and approximately $20.14 \%$ will be used by the heating industry. Coal mining, coal 


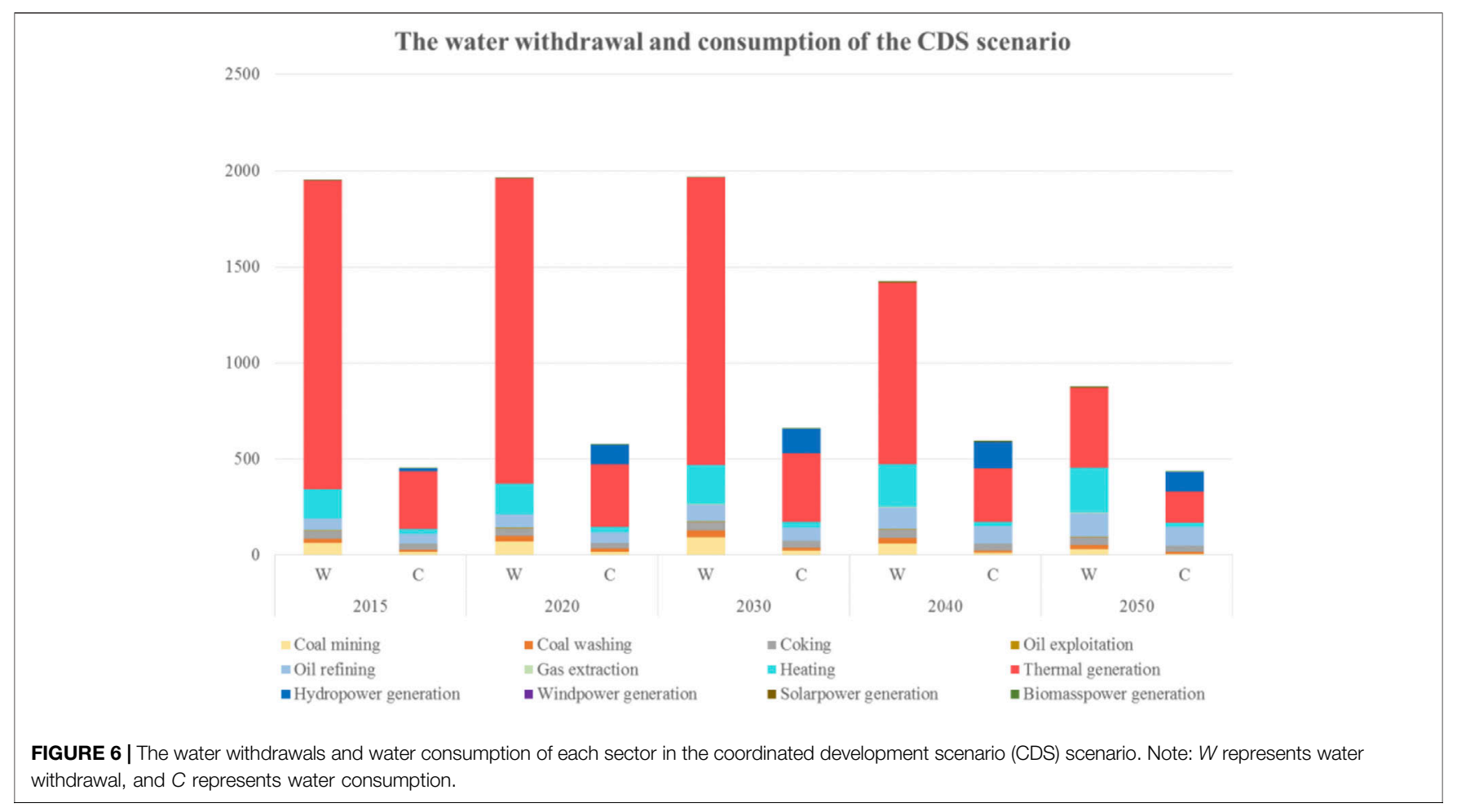

washing, coking, oil extraction, oil refining, and natural gas extraction will account for approximately $29.16 \%$ of the total water withdrawals, which is $6.85 \%$ lower than in the REF scenario. In terms of water consumption by 2050, the proportion of coking and oil refining will have increased. Thermal power generation will account for approximately $39.54 \%$, and this industry will be the sector with the largest water withdrawals and water consumption.
As shown in Figure 7, compared with the CDS scenario, the water withdrawals and water consumption for energy production decreased sharply in the SER scenario, and the water withdrawals and water consumption peaked around 2020. The water withdrawals decreased by 17.06 and $18.41 \%$ and the water consumption decreased by 46.05 and $37.96 \%$ compared with the CDS scenario in 2030 and 2050, respectively. However, in order to further reduce carbon emissions, the introduction of

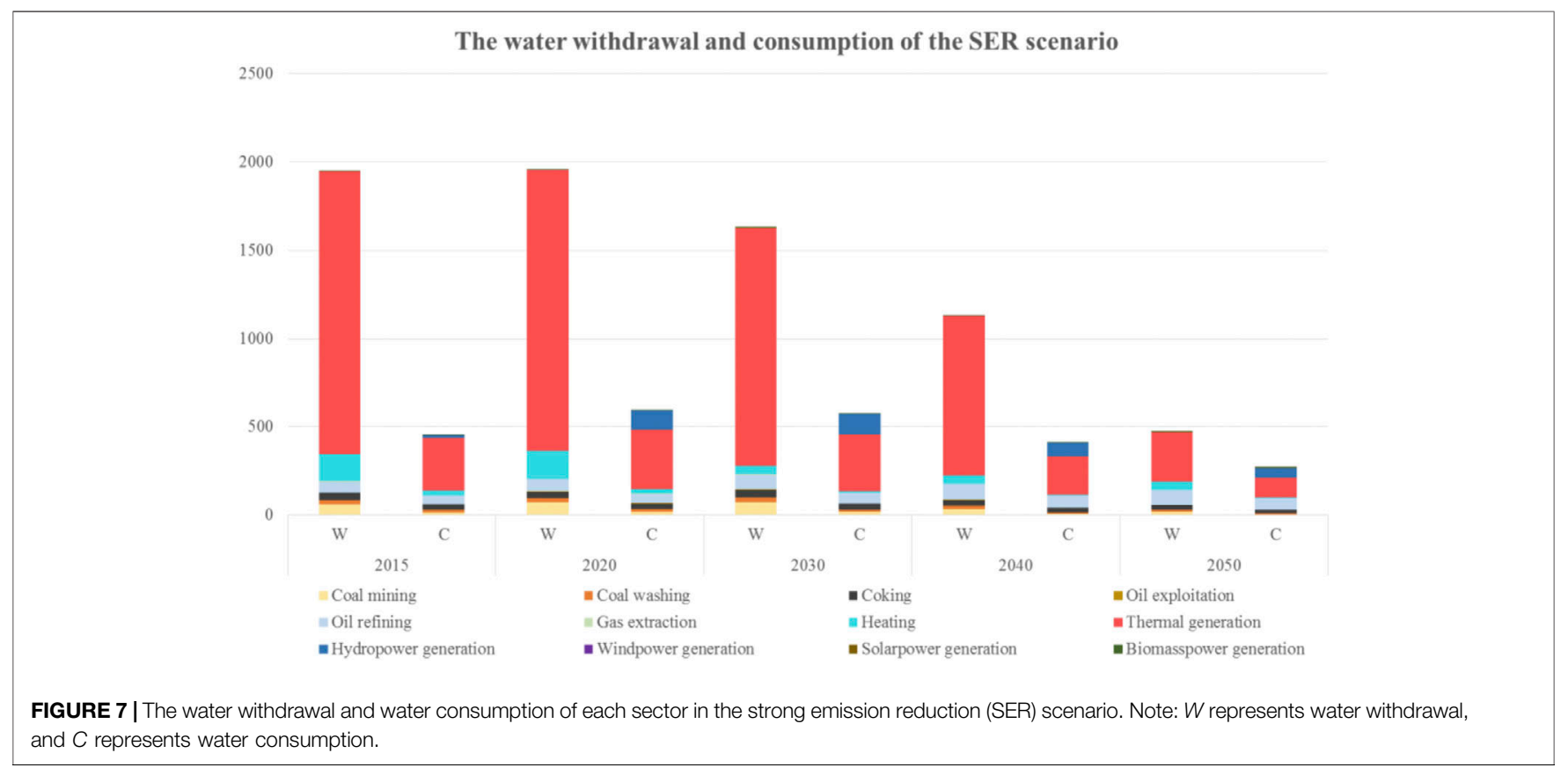


advanced CCS technology will increase from 10 to $60 \%$ from 2030 to 2050. The additional water withdrawals and water consumption required for CCS technology will be 52.34 million $\mathrm{m}^{3}$ in 2030, which will increase to 184.93 million $\mathrm{m}^{3}$ in 2050, an increase of 2.53 times compared with 2030. Although the application of CCS technology reduces carbon emissions, it increases the use of water resources and reduces the efficiency of electricity production; hence, the limits of water resources should be weighed against reductions in carbon emissions. In the SER scenario, the amount of water used in coal mining and coal washing peaked around 2030, and there was an inflection point. The amount of water used for thermal power generation peaked around 2020, and then slowly declined. The amount of water used in the coking process peaked around 2030, and other sectors continued in an upward trend, while the growth rate slowed down noticeably. In terms of water withdrawals by 2050, the results are basically consistent with the CDS scenario. The proportion of thermal power generation remained the largest. About $44.40 \%$ of the water is used for thermal power generation, and $29.44 \%$ is used by the heating industry. Coal mining, coal washing, coking, oil extraction, oil refining, and natural gas extraction account for approximately $25.66 \%$ of the total water withdrawals. In terms of water consumption by 2050, the proportion of water consumption for oil refining increased. Thermal power generation accounts for approximately $36.22 \%$ of the total water consumption, which is the largest proportion of water consumption. The proportion of water consumption for hydropower generation increased, accounting for approximately $18.34 \%$ of the total water consumption in 2050. However, this proportion was decreased in comparison to the CDS scenario; in the CDS scenario, the further development of wind energy and solar energy increased the proportion again. The thermal power generation sector remains the sector with the largest water withdrawals and water consumption, and should be considered by the local government in the future.

\section{Discussion}

Energy Transformation and Technological Innovation A comparison of the CDS scenario with the SER scenario shows that the SER scenario further improved the energy efficiency and developed renewable energy sources, such as wind energy and solar energy, to replace traditional thermal power generation. The water withdrawals by the electricity sector in the SER scenario decreased by approximately 18.02 and $32.30 \%$ compared with the CDS scenario in 2030 and 2050, respectively. The water consumption decreased by approximately 17.90 and $36.84 \%$ in 2030 and 2050, respectively. This is due to the fact that almost no water is used in wind power generation and solar power generation, and the watersaving benefits increase as the scale of development expands. Hebei Province's geographical advantages and natural resources should be fully exploited to increase the use of renewable energy. In this paper, we considered three main types of cooling techniques (oncethrough cooling, cyclic cooling, and air-cooling) whose water withdrawals and water consumption vary greatly. The results of the scenario analysis indicate that a change in cooling technology (from once-through cooling to air-cooling) will have an obvious water-saving effect, which can effectively reduce the water withdrawals and water consumption of the thermal power generation sector.

\section{Impact on the "Three Red Lines" Water Policy}

In 2011, the Ministry of Water Resources selected Hebei Province to pilot the most stringent water resources management system, the "three red lines" target system (the red line used to control the total amount of water, the red line used to control water efficiency, and the red line used to control the water function area to limit pollution). In terms of the red line used to control the total amount of water, the total water use value will be limited to 21.7, 22.1, and 24.6 billion $\mathrm{m}^{3}$ in 2015, 2020, and 2030, respectively, in Hebei Province (The State Council of the People's Republic of China, 2012).

The ratio of water use for energy production to provincial water abstraction was calculated to illustrate the impact of water use for energy production on the limited water resources in Hebei. Although the water use for energy production only accounts for a small portion (approximately $8.7 \%$ ) of the total water use in Hebei, it would have a greater impact on local water resources. Hebei is a region with a serious shortage of water resources, and the water use in agriculture is huge. An increase in water use for energy production, especially an increase in water use for traditional fossil fuel energy production and thermal power generation, will pose a serious threat to the local ecological environment. The amount of water used in agricultural and other industrial production processes will be reduced as more water will be used for energy production, which poses a high risk of local water shortages. Optimizing the industrial and energy structure, inhibiting the development of the secondary industry, vigorously developing the tertiary industry, improving energy efficiency, implementing natural gas instead of coal, developing renewable energy, increasing the proportion of renewable energy, and making use of advanced water-saving technologies will alleviate this trend. We estimated the impact of the policy measures adopted in the SER scenario on the "three red lines" water policy in Hebei. The water withdrawals for energy production accounted for approximately $8.7,12.3$, and $20.7 \%$ of the total water use control target in 2015 , 2020 , and 2030, respectively, in the REF scenario. A series of corresponding policy measures were taken in the SER scenario, where the water withdrawals accounted for approximately 8.7, 7.9, and $6.2 \%$ of the control targets, respectively. The water use for energy production in the SER scenario decreased by 4.4 and $14.5 \%$ compared with the REF scenario in 2020 and 2030, respectively. These results indicate that these policy measures can effectively save water and help to achieve the control target of the "three red lines." But it is worth noting that the water saving measures like the aircooling technology might bring a risk of high economics cost for this region. The coordinated management of energy-watereconomy needs further attention. Anyhow, air-cooling technology is still a better choice of thermal power station in the area like Hebei Province rich in coal but short of water.

\section{Uncertainty in the Scenario Analysis Results}

This study used a series of parameters that were selected in accordance with the requirements of the 13th Five-Year Plan of Hebei Province. The LEAP model was adopted to predict the 
energy production, and the water intensity was derived from other studies. The selection of parameters was too simple and was not optimized. In addition to not including all of the influencing factors, there were also uncertainties in the setting of the future parameter values for the selected driving factors, including GDP growth rate, industrial structure, population growth rate, and energy import and export volume. The economy, population, and urbanization rate of Hebei were predicted according to the overall development trend in China for the period 2015-2050. As Hebei has no perfect plan for or information that would allow us to discuss its development trend, the average development trend of China's provincial-level regions was derived from other references. It was not subdivided into the detailed terminal equipment planning of each department, thus causing uncertainty in the accuracy of the results. There is a direct relationship between energy production and import and export volume, which is significant to the model that was used in this research, and as the energy import and export volume was based on a statistical analysis of historical data on Hebei Province, it is uncertain and therefore could cause uncertainty in the estimated energy production values. The estimations of the intensity of water withdrawals and water consumption were made using a predictive analysis that considered technological progress every 10 years. Detailed changes in each year were not considered, partly due to limited data, but also because we made a general estimate for the three scenarios based on the set conditions, which would not affect the comparison between the scenarios.

There is still another limitation to this study. The water use for nuclear energy were not taken into consideration in Hebei Province, since the first planed nuclear power station in Cangzhou of Hebei hadn't been put into operation to date. But anyway, the nuclear plant is going to be a very important factor to water resource stress in Hebei Province if the planned nuclear power plants will come into service in the next couple of years. Thus, if reliable data become available, future work on this topic will be carried out thoroughly and deeply.

\section{CONCLUSIONS AND POLICY IMPLICATIONS}

\section{Conclusions}

(1) In this study, the bottom-up LEAP model was applied to estimate the water withdrawals and water consumption associated with energy production for each sector in Hebei Province from 2015 to 2050 . Our main conclusions are as follows.

(2) The energy production and the water requirements for energy production would continue to grow at a high speed in the REF scenario (the business-as-usual scenario); the energy production, the water withdrawals, and the water consumption for energy production decreased sharply in the CDS and SER scenarios compared with the REF scenario due to optimization of the industrial structure and the energy structure, inhibition of the development of the secondary industry, vigorous development of the tertiary industry, improvements in energy efficiency, implementation of natural gas instead of coal, development of renewable energy, and an increase in the proportion of renewable energy.

(3) The water withdrawals and water consumption would peak around 2030 and 2020 during the forecast period in the CDS and SER scenarios, respectively, indicating that these measures can effectively reduce energy production and water requirements. The thermal power generation sector remains the sector with the largest water withdrawal and water consumption; however, there is a decreasing trend with the implementation of policies and the development of renewable energy. The water use of the heating sector gradually increases with the improvement of people's living standards.

(4) The results of the comparison of the SER scenario and the CDS scenario indicate that advances in energy technology, optimization of the energy structure, and an increase in the proportion of renewable energy will play an increasingly significant role in Hebei's long-term development. Therefore, the development of a low-carbon economy is not only an urgent problem due to climate challenges and air pollution, but is also necessary in order to reduce the pressure on water resources. The government should adopt stricter policies to reduce the production of traditional fossil energy (especially by the coal industry), vigorously develop renewable energy technology, and reduce the pressure on Hebei's limited water resources.

(5) The selection of cooling technology for use in electricity generation should consider specific geographical factors. The promotion of air-cooling technology must consider the trade-off between energy efficiency and water use. In addition, the choice of electricity generation and cooling technologies should also consider the trade-off between funding and operating costs and between water conservation and greenhouse gas emissions. CCS technology should be carefully developed in areas where water resources are currently scarce. The trade-off between emissions reductions and water use by methods that reduce $\mathrm{CO}_{2}$ should also be carefully considered.

\section{Policy Implications}

Combing the above analysis and the industrial structure, energy structure and energy efficiency of Hebei Province, this paper put forward the following policy implications to improve energy efficiency and reduce water consumption:

Firstly, Hebei Province should speed up the adjustment of industrial structure, reduce the dependence of traditional industrial structure on energy consumption, promote the optimization of industrial structure, reduce the proportion of the primary and secondary industries gradually, develop the tertiary industry such as modern service industry vigorously, and promote the integration of the tertiary industry and other industries. Secondly, for the future development, Hebei Province should increase the proportion of cleaner alternative energy, continue to replace raw coal and coke with natural gas and electricity, improve the energy efficiency of thermal power generation, and focuses on the development of wind and solar energy. Finally, Hebei Province should increase investment in technologies, encourage the innovation in energy technologies, 
carry out the research on energy technologies, and increase the introduction and deployment of clean energy technologies on both the demand and supply, such as use cooling technology to reduce water consumption and improve energy efficiency of each sectors. At the same time, according to the current policy of Hebei Province, there may be some barriers for the above policy implications: for the adjustment of industrial structure, the large-scale industrial bases provided favorable conditions for the development of the secondary industries in Hebei Province, and it is difficult to reduce the dependence of economic development on the secondary industry in the short term. For cleaner alternative energy, there are still some problems in Hebei Province, such as insufficient development and low energy utilization of cleaner alternative energy, serious shortage of energy allocation management system. The photovoltaic power generation in Hebei Province is also in the initial stage. For energy technologies, the development of energy technologies is slow in Hebei Province, and the water saving measures like the aircooling technology need higher economic cost, while the government lacks funds for relevant investment.

\section{DATA AVAILABILITY STATEMENT}

The raw data supporting the conclusions of this article will be made available by the authors, without undue reservation.

\section{REFERENCES}

Agrawal, N., Ahiduzzaman, M., and Kumar, A. (2018). The development of an integrated model for the assessment of water and GHG footprints for the power generation sector. Appl. Energy 216, 558-578. doi:10.1016/j.apenergy.2018.02.116

Bureau for Workers' Activities (2014). Introduction and proposed goals and targets on sustainable development agenda for the post 2015 development agenda. Available at: https://sustainabledevelopment.un.org/content/documents/ 4523zerodraft.pdf (Accessed October 5, 2019).

Cai, B., Zhang, B., Bi, J., and Zhang, W. (2014). Energy's thirst for water in China. Environ. Sci. Technol. 48, 11760-11768. doi:10.1021/es502655m

Cai, W., Wang, C., Chen, J., Wang, K., Zhang, Y., and Lu, X. (2008). Comparison of $\mathrm{CO}_{2}$ emission scenarios and mitigation opportunities in China's five sectors in 2020. Energy Policy 36, 1181-1194. doi:10.1016/j.enpol.2007.11.030

Chen, C., Long, H. L., Wan, J., Jia, J. L., Li, X., and Chu, C. J. (2016). Economicenergy-industrial-environmental optimization (EEIEO) model for identification of optimal strategies-a case study of Beijing-Tianjin-Hebei region, China. IOP Conf. Ser. Earth Environ. Sci. 40, 012005. doi:10.1088/ 1755-1315/40/1/012005

Chen, H., Wang, Z., Xu, S., Zhao, Y., Cheng, Q., and Zhang, B. (2020). Energy demand, emission reduction and health co-benefits evaluated in transitional China in a $2^{\circ} \mathrm{C}$ warming world. J. Clean. Prod. 264, 121773. doi:10.1016/j. jclepro.2020.121773

China Electric Power Yearbook Editorial Committee (2016). China power yearbook 2016. Beijing, China: China Electric Power Press.

China Energy and Carbon Emission Research Group (2009). 2050 China energy and $\mathrm{CO}_{2}$ emissions report. Beijing, China: Science Press.

Clark, V., and Heaps, C. (2012). LEAP: long-range energy alternatives planning system. Available at: http://www.energycommunity.org/ documents/LEAP2011UserGuideEnglish.pdf (Accessed April 27, 2020).

Cooper, D. C., and Sehlke, G. (2012). Sustainability and energy development: influences of greenhouse gas emission reduction options on water use in energy production. Environ. Sci. Technol. 46, 3509-3518. doi:10.1021/es201901p

\section{AUTHOR CONTRIBUTIONS}

XL and GL contributed to all aspects of this work. DD and GL conducted data analysis. DD and RY wrote the main manuscript text. SL gave some useful comments and suggestions to this work. All authors reviewed the manuscript.

\section{FUNDING}

This work was supported by a grant from State Key Laboratory of Resources and Environmental Information System, Fundamental Research Funds for the Central Universities (Grant No. 2019QD01 and 2019QD03).

\section{ACKNOWLEDGMENTS}

We greatly thank "MDPI English editing” (English-15278) for the editing assistance to the paper.

\section{SUPPLEMENTARY MATERIAL}

The Supplementary Material for this article can be found online at: https://www.frontiersin.org/articles/10.3389/fenrg.2020.558536/ full\#supplementary-material

Department of Housing and Urban-Rural of Hebei (2017). Urban system planning of Hebei province (2016-2030). Available at: http://www.dzs.gov.cn/zfwz/ upload/info/20170324092335.pdf (Accessed April 25, 2020).

Emodi, N. V., Emodi, C. C., Murthy, G. P., and Emodi, A. S. A. (2017). Energy policy for low carbon development in Nigeria: a LEAP model application. Renew. Sustain. Energy Rev. 68, 247-261. doi:10.1016/j.rser.2016.09.118

Fang, D. L., and Chen, B. (2016). Linkage analysis for the water-energy nexus of city. Appl. Energy 189, 770-779. doi:10.1016/j.apenergy.2016.04.020

Hong, S., Chung, Y., Kim, J., and Chun, D. (2016). Analysis on the level of contribution to the national greenhouse gas reduction target in Korean transportation sector using LEAP model. Renew. Sustain. Energy Rev. 60, 549-559. doi:10.1016/j.rser.2015.12.164

Jin, P., Fang, D., and Chen, B. (2019). Water-energy nexus based on modified multiregional input-output model within China. Energy Procedia 158, 4092-4098. doi:10.1016/j.egypro.2019.01.826

Katta, A. K., Davis, M., Subramanyam, V., Dar, A. F., Mondal, M. A. H., Ahiduzzaman, M., et al. (2019). Assessment of energy demand-based greenhouse gas mitigation options for Canada's oil sands. J. Clean. Prod. 264, UNSP118306. doi:10.1016/j.jclepro.2019.118306

Kenney, D. S., and Wilkinson, R. (2011). The water-energy nexus in the American west. Williston, ND: Edward Elgar Publishing.

Kiparsky, M., Sedlak, D. L., Thompson, B. H., and Truffer, B. (2013). The innovation deficit in urban water: the need for an integrated perspective on institutions, organizations, and technology. Environ. Eng. Sci. 30, 395-408. doi:10.1089/ees.2012.0427

Li, W., An, C., and Lu, C. (2018). The assessment framework of provincial carbon emission driving factors: an empirical analysis of Hebei Province. Sci. Total Environ. 637-638, 91-103. doi:10.1016/j.scitotenv.2018.04.419

Li, X., Yang, L., Zheng, H., Shan, Y., Zhang, Z., Song, M., et al. (2019). City-level water-energy nexus in Beijing-Tianjin-Hebei region. Appl. Energy 235, 827-834. doi:10.1016/j.apenergy.2018.10.097

Li, Z., Fu, J., Lin, G., Jiang, D., Liu, K., and Wang, Y. (2019). Multi-scenario analysis of energy consumption and carbon emissions: the case of Hebei province in China. Energies 12, 624. doi:10.3390/en12040624 
Liu, J. G., Zhao, D. D., Gerbens-Leenes, P. W., and Guan, D. B. (2015). China's rising hydropower demand challenges water sector. Sci. Rep. 5, 11446. doi:10. 1038/srep11446

Lu, Y., Nakicenovic, N., Visbeck, M., and Stevance, A.-S. (2015). Policy: five priorities for the UN sustainable development Goals. Nature 520, 432-433. doi:10.1038/520432a

Lv, J., Li, Y. P., Shan, B. G., Jin, S. W., and Suo, C. (2018). Planning energy-water nexus system under multiple uncertainties-a case study of Hebei province. Appl. Energy 229, 389-403. doi:10.1016/j.apenergy.2018.08.010

Macknick, J., Newmark, R., Heath, G., and Hallett, K. C. (2012). Operational water consumption and withdrawal factors for electricity generating technologies: a review of existing literature. Environ. Res. Lett. 7, 189-190. doi:10.1088/17489326/7/4/045802

Mielke, E., Anadon, L. D., and Narayanamurti, V. (2010). Water consumption of energy resource extraction, processing, and conversion. Cambridge, UK: Belfer Center for Science and International Affairs. Harvard Kennedy School, Available at: http://belfercenter.ksg.harvard.edu/files/ETIP-DP-2010-15-final4.pdf (Accessed December 5, 2019).

Ministry of Water Resources of China (2015). China water resources bulletin 2014. Beijing, China: China Water and Power Press.

Nicot, J.-P., and Scanlon, B. R. (2012). Water use for shale-gas production in Texas, U.S. Environ. Sci. Technol. 46, 3580-3586. doi:10.1021/es204602t

Pate, R. C., Hightower, M., Cameron, C., and Einfeld, W. (2007). Report No.: SAND 2007-1349C. Overview of energy-water interdependencies and the emerging energy demands on water resources. Los Alamos, NM: Sandia National Laboratories.

Qin, Y., Curmi, E., Kopec, G. M., Allwood, J. M., and Richards, K. S. (2015). China's energy-water nexus-assessment of the energy sector's compliance with the " 3 Red Lines” industrial water policy. Energy Policy 82, 131-143. doi:10.1016/j. enpol.2015.03.013

Rahman, M. M., Paatero, J. V., Lahdelma, R., and Wahid, M. A. (2016). Multicriteria-based decision aiding technique for assessing energy policy elements-demonstration to a case in Bangladesh. Appl. Energy 164, 237-244. doi:10.1016/j.apenergy.2015.11.091

Shang, Y., Hei, P. F., Lu, S. B., Shang, L., Li, X. F., Wei, Y. P., et al. (2016). China's energy-water nexus: assessing water conservation synergies of the total coal consumption cap strategy until 2050. Appl. Energy 210, 643-660. doi:10.1016/j. apenergy.2016.11.008

Spang, E. S., Moomaw, W. R., Gallagher, K. S., Kirshen, P. H., and Marks, D. H. (2014). Multiple metrics for quantifying the intensity of water consumption of energy production. Environ. Res. Lett. 9, 105003. doi:10.1088/1748-9326/9/10/105003

Strzepek, K., Baker, J., Farmer, W., Schlosser, C. A., Prinn, R. G., and Reilly, J. M. (2012). Report No.: 222. Modeling water withdrawal and consumption for electricity generation in the United States. Available at: https://globalchange. mit.edu/publication/15900.

Sun, L., Pan, B., Gu, A., Lu, H., and Wang, W. (2018). Energy-water nexus analysis in the Beijing-Tianjin-Hebei region: case of electricity sector. Renew. Sustain. Energy Rev. 93, 27-34. doi:10.1016/j.rser.2018.04.111
The State Council of the People's Republic of China (2012). Report No.: 3. Opinions on the implementation of the strictest water resources management system. Available at: http://www.gov.cn/zwgk/2012-02/ 16/content_2067664.htm (Accessed March 15, 2020).

Veil, J. A., Puder, M. G., Elcock, D., and Redweik, R. J., Jr. (2004). A white paper describing produced water from production of crude oil, natural gas, and coal bed methane. Available at: https://digital.library.unt.edu/ark:/67531/ metadc780870/m2/1/high_res_d/821666.pdf (Accessed May 2, 2020).

Wang, Z., and Yang, L. (2015). Delinking indicators on regional industry development and carbon emissions: Beijing-Tianjin-Hebei economic band case. Ecol. Indicat. 48, 41-48. doi:10.1016/j.ecolind.2014.07.035

Zhang, C., and Anadon, L. D. (2013). Life cycle water use of energy production and its environmental impacts in China. Environ. Sci. Technol. 47, 14459-14467. doi:10.1021/es402556x

Zhang, C., Anadon, L. D., Mo, H., Zhao, Z., and Liu, Z. (2014). Water-carbon trade-off in China's coal power industry. Environ. Sci. Technol. 48, 11082-11089. doi:10.1021/es5026454

Zhang, Q. Q., Liu, M. S., Chi, X., Zhang, M. J., and Zhang, Y. (2013). Correlations between road density and settlement percentage coverage in Jiangsu Province, East China. Chin. J. Ecol. 32, 465-472.

Zhao, T., Liu, Z., and Zhao, C. X. (2011). Research on the prospects of low-carbon economic development in China based on LEAP model. Energy Procedia 5, 695-699. doi:10.1016/j.egypro.2011.03.123

Zhou, D., Sun, M., and Li, J. (2017). Upgrading energy structure in Hebei provincedevelopment of distributed photovoltaic power generation applications. Mod. Bus. Trade Ind. 21, 192-193.

Zhou, Y., Li, H., Wang, K., and Bi, J. (2016). China's energy-water nexus: spillover effects of energy and water policy. Global Environ. Change 40, 92-100. doi:10. 1016/j.gloenvcha.2016.07.003

Zhou, Y., Ma, M., Gao, P., Xu, Q., Bi, J., and Naren, T. (2019). Managing water resources from the energy-water nexus perspective under a changing climate: a case study of Jiangsu province, China. Energy Policy 126, 380-390. doi:10. 1016/j.enpol.2018.11.035

Disclaimer: Frontiers Media SA remains neutral with regard to jurisdictional claims in published maps and institutional affiliations.

Conflict of Interest: The authors declare that the research was conducted in the absence of any commercial or financial relationships that could be construed as a potential conflict of interest.

Copyright (c) 2020 Li, Dong, Lin, Yan and Li. This is an open-access article distributed under the terms of the Creative Commons Attribution License (CC BY). The use, distribution or reproduction in other forums is permitted, provided the original author(s) and the copyright owner(s) are credited and that the original publication in this journal is cited, in accordance with accepted academic practice. No use, distribution or reproduction is permitted which does not comply with these terms. 